\title{
SITUS GEOPARK GUNUNG SEWU GEO AREA PACITAN SEBAGAI SUMBER BELAJAR ILMU-IMU SOSIAL
}

\section{Dheny Wiratmoko, Erista Zulki Fahrudi}

STKIP PGRI Pacitan

Email: dheny.wiratmoko@gmail.com, eristazulki@gmail.com

\begin{abstract}
Abstrak
Peranan Situs Geopark Gunung Sewu Geo Area Pacitan menjadi bagian yang tidak terpisahkan ketika kita mempelajari dan mengkaji ilmu-ilmu sosial. Dalam konsep pengembangan Geopark, berorientasi pada pengembangan ilmu pengetahuan, pengembangan kebudayaan masyarakat, dan pengembangan ekonomi masyarakat.Penelitian ini menggunakan metode kualitatif,yang meliputi kegiatanobservasi, wawancara mendalam, dan dokumentasi. Untuk mendapatkan validitas data, dilakukan dengan teknik trianggulasi, yaitu trianggulasi data dan trianggulasi metode.Dalam hal ini, teknik analisis datanya menggunakan model intaraktif, yang terdiri dari reduksi data, sajian data, dan penarikan simpulan, sehingga dapat diketahui secara mendalam pemanfaatan Situs Geopark Gunung Sewu Pacitan. Berdasarkan hasil penelitian dapat disimpulkan bahwa Situs Geopark Gunung Sewu Geo Area Pacitan dapat digunakan sebagai sumber belajar ilmu-ilmu sosial. Dari beberapa situs yang diteliti memberikan informasi terkait dengan kajian kajian ilmu sosial.
\end{abstract}

Kata Kunci: Situs Geopark, Gunung Sewu, Sumber Belajar, IlmuIlmu Sosial. 


\begin{abstract}
The role of Geopark Site Mount Sewu Geo The Pacitan area becomes an integral part as we study and study the social sciences. In the concept of Geopark development, oriented to the development of science, the development of community culture, and economic development of the community. This research uses qualitative methods, which include observation, in-depth interviews, and documentation. To obtain data validity, it is done by triangulation technique, that is triangulation of data and triangulation method. In this case, data analysis technique using interactive model, consisting of data reduction, data presentation, and drawing conclusion, so it can be known in depth the utilization of Geopark Mountain Site Sewu Pacitan. Based on the results of the research can be concluded that Geopark Site Mount Sewu Geo Area Pacitan can be used as a source of learning social sciences. Of the several sites studied provide information related to the study of social studies.
\end{abstract}

Keywords: Geopark Site, Gunung Sewu, Learning Resources, Social Sciences

\title{
A. Pendahuluan
}

Indonesia adalah sebuah negara yang memiliki banyak kekayaan alam dan keanekaragaman geologinya.Indonesia diberkahi dengan bentang alamyang terdiri dari keindahan alam, tanah yang subur, hutan luas, dan berlimpah mineral. Segenap kekayaan tersebut merupakan berkah dari kondisi geologi pulaupulau penyusun negeri ini.Hal tersebut menjadikan Indonesia menjadi salah satu wilayah yang banyak dijadikan lokasi penelitian oleh para ahli Indonesia maupun dunia.

Situs Geopark merupakan sebuah konsep yang dicetuskan oleh UNESCO pada awal tahun 2000-an yang kemudian pada tahun 2004 ditindaklanjuti dengan didirikannya Global Geopark Network (GGN). Langkah tersebut merupakan bagian dari upaya UNESCO untuk mengidentifikasi kawasan yang secara geologis mendukung bagi pengembangan ilmu pengetahuan.Menurut 
UNESCO, Geopark adalah sebuah kawasan dengan fenomenafenomena geologi mengagumkan, yang meliputi arkeologi, ekologi, dan budaya.

Situs Goepark Gunung Sewu menjadi anggota jaringan geopark dunia yang ke 117 sejak disahkan oleh Global Geopark Network pada tahun 2015.Hal ini menjadikan Indonesia mempunyai dua geopark dengan reputasi dunia, setelah Geopark Batur juga ditetapkan untuk pertama kalinya di Indonesia yaitu pada tahun 2012. Dengan raihan ini pula, Situs Geopark Gunung Sewu kian mantap menjadi kawasan yang memiliki rekam jejak penelitian yang panjang.Nilai estetika bentang alam karst di Gunung Sewu telah dikenal orang sejak dulu.Franz Junghuhn adalah orang pertama yang merekam keindahan alam ini melalui sketsa-sketsanya. Setelah proses itu, maka kian banyak orang yang meneliti Gunung Sewu.

Situs Geopark merupakan keterpaduan konsep untuk menyejahterakan masyarakat lokal berbasis konservasi warisan geologi (geoheritage). Dalam Geopark setidaknya harus terkandung 3 unsur penting yaitu: pendidikan, ekonomi, dan konservasi. Di antara ketiga unsur tersebut merupakan bagian yang saling terkait, dan saling mendukung antara unsur yang satu dengan unsur yang lain.

Berdasarkan hal diatas, Situs Geopark Gunung Sewu Pacitan memiliki ketiga unsur potensi tersebut, sehingga memungkinkan untuk dijadikan kawasan Geopark berkelas dunia.Berhubungan dengan hal tersebut, Situs Geopark Gunung Sewu Pacitan telah diakui oleh UNESCO sebagai Situs Geopark dunia dari Indonesia. 
JIPSINDO No. 2, Volume 4, September 2017

\section{Tinjauan Umum Situs Geopark Gunung Sewu}

Kawasan Situs Gunung Sewu memiliki kekhasan dan keunikan yang meliputi keragaman geologi, budaya, dan hayati.Situs Geopark Gunung Sewu merupakan kawasan karst tropik yang sangat luas.Tingginya nilai strategis kawasan karst Gunung Sewu menyebabkan pemerintah Indonesia menetapkan daerah ini sebagai kawasan ekokarst. Situs Geopark Gunung Sewu secara administratif terletak di wilayah Pulau Jawa, tepatnya berada di tiga wilayah kabupaten yaitu Gunung Kidul (Daerah Istimewa Yogyakarta), Wonogiri (Jawa Tengah), dan Pacitan (Jawa Timur). Wilayah Situs Geopark Gunung Sewu merupakan bagian dari zona Pegunungan Selatan Pulau Jawa yang terbentang dari Barat sampai ke Timur, dimulai dari Pantai Parangtritis hingga Teluk Pacitan.

Pulau Jawa terletak tepat di selatan garis khatulistiwa antara $6^{\circ}$ hingga $9^{\circ}$ Lintang Selatan serta $105^{\circ}$ hingga $114^{\circ}$ Bujur Timur. Wilayah Pulau Jawa luas permukaannya mencapai 134.000 $\mathrm{Km}^{2}$. Wilayah Pulau Jawa sangat padat populasi penduduknya disebabkan karena keseburan tanah vulkanisnya yang sejak dulu terus-menerus menarik minat banyak penduduk.

Secara geografis, letak Pulau Jawa di sebelah utara berbatasan dengan Laut Jawa, di sebelah selatan berbatasan dengan Samudera India, sebelah timur berbatasan dengan Selat Bali, dan di sebelah barat berbatasan dengan Selat Sunda. Pulau Jawa yang memanjang pada arah timur-barat, membentang sepanjang $1000 \mathrm{Km}$ dengan lebar antara 180-180 Km.

Berdasarkan hasil-hasil penelitian-penelitian sebelumnya, diketahui bahwa sejarah geologis Pulau Jawa masih relatif muda, tersusun dari tanah zaman tersier, zaman Kuarter, dan zaman sekarang. Berdasarkan poros utama barat-timur, Pulau Jawa 
dapat dibagi ke dalam tiga lajur yang sejajar.Lajur utara yang dibatasi oleh Pantai Laut Jawa dengan dataran rendah dan perbukitan. Lajur tengah yang bersifat vulkanis di mana terdapat barisan tengah gunung berapi, dan lajur selatan yang dibatasi oleh Samudera Hindia di mana timbul sedimen-sedimen purba dan juga ditambah batu gamping yang mengalami karstifikasi seperti yang terdapat di daerah Gunung Sewu Pacitan (Hubert Forestier, 2007: 81). Taman Nasional Gunungsewu yang telah ditetapkan sebagai jaringan geopark dunia (Global Geopark Network) tidak hanya meliputi rangkaian pegunungan karst di Gunungkidul, DIY tetapi juga membentang hingga Kabupaten Wonogiri, Jawa Tengah serta Kabupaten Pacitan, Jawa Timur.

Geopark Gunung Sewu merupakan salah satu geopark di indonesia yang telah diresmikan dan diakui keberadaanya oleh UNESCO pada tahun 2015. Kawasan Geopark Gunung Sewu meliputi tiga kabupaten yaitu Kabupaten Pacitan, Kabupaten Wonogiri dan Kabupaten Wonosari. Kabupaten Pacitan memiliki tiga belas objek wisata yang termasuk ke dalam kawasan Geopark Gunung Sewu, ketiga belas objek wisata tersebut merupakan situs geologi dan situs budaya. Objek wisata yang berupa situs geologi adalah pantai klayar, pantai teleng ria, pantai srau, pantai watu karung, gua gong, gua tabuhan, gua luweng ombo, gua luweng jaran, serta sungai song terus. Objek wisata yang termasuk ke dalam situs budaya adalah kesenian wayang beber dan upacara ceprotan. Lokasi objek wisata yang termasuk ke dalam kawasan Geopark Gunung Sewu di Kabupaten Pacitan menyebar pada empat Kecamatan yaitu Kecamatan Donorojo, Kecamatan Punung, Kecamatan Pringkuku dan Kecamatan Pacitan. 


\section{Tinjauan Geografis Situs Geopark Gunung Sewu Geo Area Pacitan}

Situs Geopark Gunung Sewu Geo Area Pacitan adalah kawasan yang terdiri dari bentang alam yang berupa bukit-bukit batu gamping. Keindahan alamnya, keunikan budaya, dan kehidupan masyarakat, menjadikan kawasan ini sebagai bagian dari situs warisan alam yang menarik untuk dijadikan bahan penelitian. Pacitan merupakan bagian gugusan dari Pegunungan Seribu (Gunung Sewu),yang telah diakui dan dinobatkan menjadi kawasan karst dunia. Secara geografis, wilayah Kabupaten Pacitan terletak antara $110^{\circ} 55^{\prime \prime}-111^{\circ} 25^{\prime \prime}$ Bujur Timur dan $7^{\circ} 55^{\prime \prime}-8^{\circ}$ 17". Kondisi fisik Kabupaten Pacitan terdiri dari daerah pegunungan dan perbukitan yang terdiri dari $85 \%$ perbukitan, dalam bentuk gunung-gunung kecil sekitar 500 buah.

Wilayah Pacitan merupakan daerah pegunungan yang terletak pada ujung timur Pegunungan Seribu. Tanah Pegunungan Seribu memiliki ciri khas yang tanahnya didominasi oleh endapan gamping bercampur koral. Endapat tersebut kemudian mengalami pengangkatan. Endapan-endapan tersebut kemudian mengalami erosi oleh sungai maupun perembesan air hingga membentuk suatu pemandangan karst yang meliputi ribuan bukit kecil.Ciriciri pegunungan karst ialah berupa bukit-bukit berbentuk kerucut atau setengah bulatan (Tim Perumus Hari Jadi Kabupaten Pacitan, 1994: 7).

Sejarah Kabupaten Pacitan sudah berlangsung sangat lama, tepatnya berlangsung sejak masa prasejarah (masa praaksara). Kabupaten Pacitan sangat identik dengan kehidupan masa

prasejarah Indonesia. Di wilayah Kabupaten Pacitan, temuan benda-benda arkeologi banyak ditemukan, benda-benda arkeologi 
Dheny Wiratmoko, Erista Zulki Fahrudi

tersebut di antaranya berupa artefak alat litik dan fosil-fosil prasejarah.

Dengan diketemukannya artefak yang sangat beragam ini memberikan petunjuk, bahwa tempat-tempat di Pacitan, khususnya di sekitar Sungai Baksoka, diidentifikasi sebagai pusat perbengkelan pembuatan peralatan manusia prasejarah.Dalam ilmu pengetahuan budaya, kebudayaan yang tersebar di daerah Kabupaten Pacitan itu diperkirakan merupakan salah satu di antara kebudayaan paling awal perkembangannya di Indonesia.Kebudayaan tersebut kemudian terkenal dengan istilah Kebudayaan Pacitanian (Pacitanian Culture).

Pada Endapan aluviumnya, van Heekeren menemukan banyak sekali artefak Budaya Pacitanian dari zaman palaeolitikum (Hanung Samodra, Dkk., 2015: 25 ). Di Situs Sungai Baksoka banyak ditemukan artefak batu dari zaman palaeolitikum.Sungai Baksoka diyakini merupakan "bengkel" kapak genggam palaeolitik.

Lingkungan geografis Pegunungan Seribu yang terdiri dari pegunungan karst memiliki persebaran situs dengan keragaman budaya yang secara teknologi menggambarkan suatu garis evolusi budaya dari bentuk-bentuk kasar menuju ke arah yang lebih sempurna. Keragaman tersebut mencerminkan keragaman sejarah penghunian yang sangat panjang, sejak kehadiran manusia untuk pertama kali muncul pada tingkat budaya palaeolitikum, mesolitikum, dan neolitikum (Tim Perumus Hari Jadi Kabupaten Pacitan, 1994: 8).

Kawasan Geopark merupakan wilayah geografis dimana situs-situs warisan geologis dan budaya merupakan bagian upaya perlindungan, pendidikan, dan pengembangan berkelanjutan. Kawasan geopark bertujuan untuk melidungi warisan geologis 
untuk dijadikan sebagai sarana pendidikan dengan konsep pengembangan yang berkelanjutan. UNESCO mendefinisikan Geopark sebagai sebuah kawasan yang memiliki unsur-unsur geologi terkemuka (outstanding) termasuk nilai arkeologi, ekologi dan budaya yang ada di dalamnya, dimana masyarakat setempat diajak berperan-serta untuk melindungi dan meningkatkan fungsi warisan alam. Melalui Geopark, warisan geologi itu digunakan untuk mendorong kesadaran masyarakat atas isu-isu yang dihadapinya berkaitan dengan dinamika kebumian yang terjadi di sekitar mereka (Kevin \& Suroso, 2014).

Situs Geopark Gunung Sewu Geo Area Pacitan dari sisi sejarah dan arkeologi mengandung kekomplekan fenomena alam. Kawasan karst yang terbentuk di wilayah Situs Geopark Geo Area Pacitan memungkinkan peluang untuk dilakukan penelitian terhadap sejarah perkembangan masyarakat, berbasis pada keunikankawasan karst dan situs-situs yang ditinggalkan. Bentuk situs sejarah dan arkeologi yang dominan terdapat di Pacitan adalah situs gua dan ceruk (song), dan juga kawasan air (laut/sungai).

Geopark gunung sewu di Kabupaten Pacitan merupakan kawasan wisata yang pengembangannya harus sejalan dan bersinergis dengan fungsinya. Hal ini dikarenakan geopark merupakan kawasan situs geologi yang keberadaannya harus dilindungi dan dikembangkan dengan konsep yang berkelanjutan. Sebagaimana tujuan geopark untuk tidak memindah maupun mengubah situs dari tempat aslinya, maka pengembangan kawasan geopark gunung sewu hendaknya dilakukan melalui keterlibatan masyarakat lokal. Salah satu alasan pengembangan kawasan Geopark Gunung Sewu dengan melibatkan masyarakat lokal selain untuk melindungi keberadaan situs geopark juga 
untuk menghindari adanya ketimpangan dalam pengembangan masing-masing objek wisata yang termasuk ke dalam kawasan Geopark Gunung Sewu di Kabupaten Pacitan. keberadaan kawasan Geopark Gunung Sewu yang menyebar di empat kecamatan menyebabkan terjadinya ketimpangan dalam pengembangan objek wisata kawasan Geopark Gunung Sewu di Kabupaten Pacitan.

\section{Metode Penelitian}

Penelitian ini menggunakan metode penelitian kualitatif. Menurut Sugiyono (2013: 1), penelitian kualitatif adalah penelitian yang digunakan untuk meneliti pada kondisi objek yang alamiah, di mana peneliti adalah sebagai instrumen kunci, teknik pengumpulan data dilakukan secara trianggulasi (gabungan), analisis data bersifat induktif, dan hasil penelitian kualitatif lebih menekankan makna dari pada generalisasi.

Strategi penelitian yang digunakan dalam penelitian ini adalah penelitian studi kasus. Jenis studi kasus dalam penelitian ini adalah studi kasus tunggal. Menurut Sutopo (2007: 140), suatu penelitian disebut sebagai studi kasus tunggal, apabila penelitian tersebut terarah pada sasaran dengan satu karakteristik. Artinya, penelitian tersebut hanya dilakukan pada satu sasaran (satu lokasi atau satu subjek).

Data atau informasi yang dikumpulkan dan dikaji dalam penelitian ini sebagian besar adalah data kualitatif, yang digali dari beberapa sumber data, di antaranya melalui wawancara mendalam kepada narasumber. Dalam kegiatan penggalian data juga melalui observasi lapangan di beberapa lokasi Situs Geopark Untuk melengkapi data yang diperlukan, juga dikaji beberapa 
literatur dan dokumen, terkait dengan Situs Geopark Gunung Sewu Geo Area Pacitan.

Cuplikan berkaitan dengan pemilihan dan pembatasan jumlah serta jenis dari sumber data yang akan digunakan dalam penelitian. Peneliti memilih informan yang dianggap mengetahui informasi dan masalahnya secara mendalam dan dapat dipercaya untuk menjadi sumber data yang mantap sehingga cuplikan dalam penelitian ini lebih bersifat purposive sampling atau criterion-based selection (Sutopo, 2006: 64). Kegiatan analisis data lebih ditekankan untuk mendeskripsikan data yang ditemukan di lapangan. Secara umum, terdapat tiga proses analisis data (Miles \& Huberman, 1984: 21) yaitu: Reduksi data adalah proses pemilihan, pemfokusan, penyederhanaan, dan abstraksi data dari catatan lapangan. Tahapan selanjutnya adalah menyajikan sekumpulan data yang tersusun dan memberi kemungkinan adanya penarikan simpulan dan pengambilan tindakan. Dalam langkah selanjutnya yaitu penarikan simpulan.

\section{Karakteristik Situs Geopark Gunung Sewu Pacitan Geo Area Pacitan}

Dalam kaitannya dengan mempelajari ilmu-ilmu sosial, hal yang sering muncul pertama kali adalah terkait kehidupan manusia dan relasi kebudayaannya. Dalam dinamika kehidupan manusia, aspek geografi kesejarahan sudah berlangsung dalam masa yang sangat panjang. Konstruksi bumi di kawasan Indonesia mengalami beberapa perubahan yang jelas mempengaruhi pola kehidupan manusia beserta relasi kebudayaannya. Perubahan itu di antaranya disebabkan oleh gerakan pengangkatan kulit bumi,erosi atau proses pengikisan lapisan kulit bumi yang disebabkan oleh angin, air hujan, dan aliran air sungai, serta 
Dheny Wiratmoko, Erista Zulki Fahrudi

vulkanisme atau kegiatan gunung berapi.Peranan Situs GeoparkGunung Sewu Geo Area Pacitanmenjadi bagian pendukung munculnya suatu kebudayaan manusia yang kelak akan berpengaruh terhadap peradaban yang dihasilkan di wilayah tersebut.

Situs Geopark Gunung Sewu Geo Area Pacitan adalah bentang geologi berbentuk batuan karst.Dalam konteks ini, karst merupakan istilah dari bahasa Yugoslavia. Istilah ini merujuk pada wilayah yang terdiri dari batuan yang mudah larut seperti batu gamping. Karst dapat diartikan sebagai bentang alam yang berkembang pada batuan karbonat akibat proses kartstifikasi (pelarutan) selama ruang dan waktu geologi. Karst adalah daerah kapur yang menampakkan bentuk-bentuk hasil pelapukan ataupelarutan atau daerah batuan kapur atau batuan dolomite yang topografinya menunjukkan gejala khas akibat pelapukan kimia pada batuan (Argyo Demartoto, Dkk, 2014: 15).Karst hanya terdapat didaerah yang wilayahnya terdiri dari pegunungan. Wilayah karst merupakan wilayah penyerapan air yang baik, kerena permukaan karst retak-retak, dengan demikian air akan mudah meresap dan mengalir ke permukaan di bawahnya.

Topografi undak berlereng curam mendominasi pinggiran selatan kawasan Gunung Sewu yang berbatasan langsung dengan Samudera Hindia. Bagian utara dibatasi dengan pematang pegunungan yang tersusun oleh batuan gunung api, karstika asal gunung api, dan batuan beku sisa-sisa kegiatan gunung api purba. Di bawah permukaan tanah berkembang sistem goa, baik berupa goa horizontal gua vertikal, atau gabungan di antara keduanya.

Kawasan karst Gunung Sewu merupakan perbukitan batu gamping yang berumur sekitar 2 juta tahun yang lalu yang 
mengalami pengangkatan dari dasar laut ke permukaan.Pengangkatan ke atas permukaan laut ini membuat batu gamping mengalami proses pelarutan oleh air membentuk bentang alam karst. Karstifikasi terus berlangsung sampai sekarang, menghasilkan bentukan morfologi seperti bukit, lembah, dan lekuk-lekuk topografi.

Karst Gunung Sewu adalah tipe karst tropis yang bercirikan bukit-bukit yang berbentuk setengah bola dan berlereng cembung. Proses pembentukan bentang alam di kawasan Gunung Sewu dikendalikan oleh struktur geologi seperti patahan dan retakan. Patahan dan retakan batu-batuan tersebut memfasilitasi masuknya air hujan ke dalam lapisan batu gamping yang lebih dalam. Karstifikasi tidak hanya terjadi di permukaan saja, tetapi juga di bawah permukaan tanah, sehingga akhirnya membentuk sistem goa.Selain itu pelarutan di bawah permukaan tanah selama ratusan ribu tahun juga menghasilkan lorong-lorong goa dan berbagai jenis ornamen atau hiasan goa seperti stalagtit, stalagmit dan sebagainya.

\section{Situs di Kawasan Geopark Gunung Sewu Geo Area Pacitan Sebagai Sumber Belajar Ilmu Sosial.}

Indonesia adalah sebuah negara besar yang mempunyai warisan budaya yang beragam dan warisan prasasti alam yang berupa situs cagar budaya dan situs sejarah yang sangat mengagumkan. Hampir di setiap penjuru tanah air Indonesia terdapat peninggalan situs dari berbagai periode dengan karakteristik yang berbeda pula. Dalam disiplin ilmu sejarah, sumber primer (primary sources) merupakan bagian dari bukti tentang masa lampau yang menjadi bahan sumber kajian, yang menjadi tumpuan, apakah suatu peristiwa, kejadian, ataupun 
fenomena sejarah dapat direkonstruksi. Menurut Elton, dalam Mona Lohanda (2011: 164), tanpa bukti tentang masa lampau, ilmu sejarah tidak berarti apa-apa, bahkan tuntutan keilmuan tidak akan mungkin dipenuhi, karena “...the study of history consists of debates between the historian and his evidence, between different students of history, between the historian and his own society. Dari sumber primer, sejarawan memperoleh dukungan bukti tentang apa yang sedang dikajinya, dan dari telaah sumber, diketemukan sejumlah fakta bersama data pendukungnya.

Sejarawan berkepentingan untuk melakukan seleksi, analisis, penafsiran dan menyajikan fakta dalam tulisan sejarah. Dalam disiplin ilmu sejarah, penafsiran dan penjelasan berawal dari pemahaman akan masalah dan kemampuan menafsir sumber sejarah. Dalam kenyataannya, sumber sejarah itu bisa berarti teks, bisa berarti ragam bentuk, alegori, sampai kepada tradisi dan kondisi historis yang melahirkan sumber sejarah tersebut (Mona Lohanda, 2011: 97-98.

Dari data-data artefaktual yang didapatkan, dapat diperkirakan bahwa pola kehidupan budaya palaeolitik cenderung berada di alam terbuka dan terletak di sekitar sungai. Pada masa itu, manusia hidupnya secara berkelompok, dengan mata pencaharian berburu dan meramu. Dalam kehidupan sosialnya tampaknya telah ada pembagian kerja antara laki-laki dan perempuan. Kaum laki-lakinya berburu dan kaum perempuannya mengumpulkan makanan. Pola itu mengalami perkembangan sejalan dengan perkembangan akal manusia. Bila dalam budaya Palaeolitik kehidupan berada di alam terbuka, pada zaman berikutnya yaitu zaman mesolitik mereka telah memanfaatkan gua, ceruk atau relung-relung di lereng pegunungan secara alami. 
Lingkungan geografis Pegunungan Seribu yang terdiri dari pegunungan karst memiliki persebaran situs dengan keragaman budaya yang secara teknologi menggambarkan suatu garis evolusi budaya dari bentuk-bentuk kasar menuju ke arah yang lebih sempurna. Keragaman tersebut mencerminkan keragaman sejarah penghunian yang sangat panjang, sejak kehadiran manusia untuk pertama kali muncul pada tingkat budaya palaeolitikum, mesolitikum, dan neolitikum (Tim Perumus Hari Jadi Kabupaten Pacitan, 1994: 8). Di antara situs-situs purba yang tersebar di Jawa, Situs Sungai Baksoka terletak di wilayah Kabupaten Pacitan, yaitu merupakan salah satu situs terpenting dengan penemuan historisnya dan kandungan artefaknya yang padat dan beragam. Publikasi Von Koenigswald pada Buletin of the Raffles Museum menjadikan situs ini mendapat perhatian dari para ahli hingga menjadi sasaran penelitian yang tidak berkesudahan (Daud Aris Tanudirdjo, dkk, 2012: 110).

\section{Kesimpulan}

Berdasarkan hasil pembahasan di atas, maka dapat disimpulkan bahwa pemanfaatan Situs Geopark Gunung Sewu Geo Area Pacitan perlu dimaksimalkan. Dalam konsep pengembangan Geopark, yang berbasis pada pengembangan ilmu pengetahuan, pengembangan kebudayaan masyarakat, dan pengembangan ekonomi masyarakat, sangat sesuai dengan kajian pembelajaran ilmu sosial.Dalam pengembangan ilmu pengetahuan, beberapa situs memberikan informasi atau bahan bagi penelitian keilmuan terkaitdengan kajian ilmu sosial, di antaranya beberapa situs sejarah dan geologi yang ada.Terkait dengan pengembangan kebudayaan masyarakat, beberapa wilayah menunjukkan atau memberikan bukti dinamika terbangunnya 
Dheny Wiratmoko, Erista Zulki Fahrudi

pusat-pusat peradaban manusia sejak zaman dahulu sampai zaman sekarang. Terkait dengan pengembangan ekonomi, beberapa tempat dijadikan sebagai pusat keekonomian masyarakat baik terkait salah satunya terwujud dalam pengembangan pariwisata.

Pada konteks pembelajaran ilmu-ilmu sosial, Situs Geopark Gunung Sewu Geo Area Pacitan memungkinkan untuk dijadikan sebagai sumber belajar.karena di dalamnya terkandung beberapa informasi yang memberikan pemahaman dan penjelasan terkait kajian ilmu sosial, khususnya di Indonesia. Situs Geopark Gunung Sewu Geo Area Pacitan juga dapat dimanfaatkan sebagai sarana pembelajaran edukatif berbasis riset dalam upaya untuk memahami kehidupan manusia serta kebudayaan pendukungnya.

\section{Daftar Pustaka}

Argyo Demartoto, Dkk. 2014. Habitus Pengembangan Pariwisata; Konsep dan Aplikasi. Surakarta: UNS Press.

Daud Aris Tanudirdjo, Dkk. 2012.Indonesia Dalam Arus Sejarah; Prasejarah. Jakarta: Ichtiar Baru Van Hoeve.

Forestier, Hubert. 2017. Ribuan Gunung, Ribuan Alat Batu Prasejarah Song Keplek Gunung Sewu Jawa Timur. Jakarta: Gramedia.

Hanang Samodra, Dkk. 2015. "Gunung Sewu Mendunia Lagi". Geomagz.Vol. 5 No. 4 Desember 2015. Jakarta: Badan Geologi, Kementerian Energi dan Sumber Daya Mineral.

Kevin, Fabryan Masrul \& Suroso Studi Proses Pengajuan Kawasan Geopark Parahyangan Di Jawa Barat Sebagai Anggota Global Geopark Network Unesco. Jurnal Perencanan Wilayah dan Kota A SAPPK V3N1

Miles, M. B. \& Huberman, A. M. 1984.Qualitative Data Analisys: A Sourcebook of New Methods. Beverly Hills, SA: Sage Publications. 
JIPSINDO No. 2, Volume 4, September 2017

Mona Lohanda. 2011.Membaca Sumber Menulis Sejarah. Yogyakarta: Ombak.

Peraturan Daerah Kabupaten Pacitan tahun 2013 tentang kepariwisataan. (Online), (http://www.pacitan.go.id) Diakses pada 2 Februari 2016

Sugiyono. 2012. Memahami Penelitian Kualitatif. Bandung: ALFABETA.

Sutopo, H. B. 2006. Metodologi Penelitian Kualitatif; Dasar Teori dan Terapannya dalam Penelitian. Surakarta: Sebelas Maret University Press.

Tim Perumus Hari Jadi Kabupaten Pacitan. 1994. Hari Jadi Kabupaten Pacitan Dalam Perspektif Sejarah Indonesia. Pacitan: Pemerintah Kabupaten Daerah Tingkat II Pacitan. 